\title{
The 2015, 2016, and 2017 Best Diversity Papers: Summary and Perspective
}

\section{Dr. Janet Callahan, Boise State University}

Janet Callahan is Chair and Professor of the Micron School of Materials Science and Engineering at Boise State University. Dr. Callahan received her Ph.D. in Materials Science, M.S. in Metallurgy, and B.S. in Chemical Engineering from the University of Connecticut. Her research interests include diversity, retention, mathematics and materials science teaching and learning, first-year programs, accreditation, and faculty development.

\section{Dr. Stephanie Farrell, Rowan University}

Dr. Stephanie Farrell is Professor and Founding Chair of Experiential Engineering Education at Rowan University (USA) and was 2014-15 Fulbright Scholar in Engineering Education at Dublin Institute of Technology (Ireland). From 1998-2016, Stephanie was a faculty member in Chemical Engineering at Rowan. Dr. Farrell has contributed to engineering education through her work in experiential learning, focusing on areas of pharmaceutical, biomedical and food engineering. She has been honored by the American Society of Engineering Education with several teaching awards such as the 2004 National Outstanding Teaching Medal and the 2005 Quinn Award for experiential learning.

\section{Dr. Adrienne Robyn Minerick, Michigan Technological University}

Adrienne Minerick is the Associate Dean for Research \& Innovation in the College of Engineering and Assistant to the Provost for Faculty Development at Michigan Tech. She received her M.S. and Ph.D. from the University of Notre Dame and B.S. from Michigan Tech. Adrienne's research interests include electrokinetics, predominantly dielectrophoretic characterizations of cells, and the development of biomedical microdevices. She earned a NSF CAREER award and was nominated for Michigan Professor of the Year in 2014. Research within her Medical micro-Device Engineering Research Laboratory (M.D. - ERL) also inspires the development of Desktop Experiment Modules (DEMos) for use in chemical engineering classrooms or as outreach activities in area schools (see www.mderl.org). Adrienne is past Chair of ASEE's Diversity Committee and past PIC I Chair; she has previously served on WIED, ChED, and NEE leadership teams and has contributed to over 40 ASEE conference proceedings articles. 


\title{
The Top Five Diversity Papers of 2015, 2016 and 2017: A Review
}

\begin{abstract}
This paper contains a summary and review of the Best Diversity Paper nominations from 2015, 2016 and 2017 - since the inception of the Best Diversity Paper, established in 2015. These papers included nominations from 35 different groups, including 30 divisions, one committee, and four regions, representing a wide-angle perspective on how individual professions study their engineering education profession as it relates to diversity and inclusiveness. Each year, the nominations resulted in five or six finalists arising from different divisions which included the K12 and Pre-College Engineering, First Year Programs, Liberal Education/Engineering and Society, Mechanical Engineering, Entrepreneurship and Engineering Innovation, and Multidisciplinary Engineering Divisions in 2015, the Civil Engineering, Chemical Engineering, Educational Research and Methods, Engineering Ethics, Women in Engineering Division and the Pacific Southwest Section in 2016, and the Aerospace Division, Diversity Committee, Liberal Education/Engineering \& Society Division, Mathematics Division, and Student Divisions in 2017.
\end{abstract}

\section{Introduction}

The ASEE Diversity Committee (ADC) is one of twelve Advisory Committees to the American Society of Engineering Education. Established in 2011 with the goal to increase diversity and inclusiveness in the engineering profession, in 2017 it is comprised of 15 members across various divisions. An excerpt from the ADC's broad Statement on Diversity [1] expresses that "ASEE believes that diversity and inclusiveness enriches and is essential to educational experiences and innovations that drive the development of creative solutions in addressing the world's challenges." With the goal of increasing diversity and inclusiveness in the engineering profession, the committee organizes several types of diversity-related conference sessions such as panels, round tables, workshops and training sessions such as Safe Zone training. The ADC has a vision, mission and published strategic plan, [2] and is an entity to which authors can directly submit papers.

The development of, and institutionalization of the Best Diversity Paper award within ASEE was a major undertaking that required drafting of the process for soliciting and identifying best papers, judging them on a consistent rubric, and disseminating the top papers. The ASEE Diversity Committee crafted a proposal, vetted it internally, worked with ASEE IT staff to customize the paper handling system, Monolith, and then vetted with the ASEE Board of Directors. The ASEE Board of Directors approved the award and institutionalized it as an annual, standing award recognized at the same monetary and visibility level as all other national Best Paper Awards. In anticipation of topics covering a variety of topics, such as ethnicity, gender, first generation status, international, and socio-economic diversity, the rubric was designed to be broad and not emphasize one dimension of diversity over another. 
Beginning in January, 2015, the ADC widely distributed a call to all divisions, sections and zones, asking them to nominate a "Best Diversity Paper." The motivation of the award is to enhance the visibility and sustainment of actions in support of diversity, and to identify highly impactful efforts by ASEE authors that broaden participation in engineering and influence the inclusive, diverse future of engineering. From the set of papers submitted, which is substantial, a review committee identifies the top five papers, and invites the authors to present in a special section of the sessions organized by the ADC. Using oral presentations as an additional level of review, in the end a final "Best Diversity Paper" is selected. While all finalists receive an award, as well as the recognition that comes from the invitation to present, it should be noted that by the act of a division's nomination, a broad array of authors receive recognition of their efforts to engage and promote the pursuit of engineering education and engineering careers with those individuals who have been historically under-represented within engineering.

The ASEE Board authorized 2014-2015 as the Year of ACTION on Diversity, "wherein members will discuss, engage, and highlight individual and collective activities that serve to advance the Society's diversity efforts and inclusivity." [1] The 2015 Diversity Best Paper solicitation for nominations (Appendix) states that the award strives to enhance the visibility and sustainment of actions in support of diversity. It goes on to point out that "engineering is empowering society in unprecedented ways. It is at the core of innovation and can address Grand Challenges facing the US and the world. In order for the engineering discipline to reach its full potential, however, the engineering education community and the engineering profession must better include all segments of our society. In particular, engineering must actively engage and help promote the pursuit of engineering education and engineering careers with those individuals who have been historically under-represented within engineering. ASEE believes that diversity and inclusiveness is essential to enriching educational experiences and innovations that drive the development of creative solutions in addressing the world's challenges. We learn from experiences, beliefs, and perspectives that are different from our own. Diversity, both intellectually and socially, fuels innovation and the development of imaginative and enduring solutions to global problems."

Annually, 5 to 7 papers are selected for awards that are presented at the annual conference for which the papers were submitted. Awards are presented in a dedicated session for the top 5 to 7 selected best diversity papers; during this session the authors present their papers in a session organized by the ASEE Diversity Committee. The best paper/presentation each year is identified and forwarded to ASEE. This finalist paper is presented alongside the PIC best papers at the following annual conference.

A total of 59 papers were nominated for the Best Diversity Paper in 2015, 2016 and 2017, across 35 divisions, committees and zones. Starting in 2017, the ASEE Diversity Committee (ADC) permitted nominations from papers submitted directly to ADC, as these papers were otherwise unrepresented for nominations by other divisions.

Table 1 summarizes the divisions as a function of time, relative to nominations. Five divisions have nominated papers in each of the three possible years; eleven divisions have nominated papers for two years out of the three possible, and 22 divisions have once nominated a paper, see Table 1. The finalist divisions whose papers are reviewed herein, are bolded. 


\begin{tabular}{|c|c|c|}
\hline \multicolumn{3}{|c|}{ Year } \\
\hline 2015 & 2016 & 2017 \\
\hline \multicolumn{3}{|c|}{ Committees } \\
\hline & & ASEE Diversity Committee \\
\hline \multicolumn{3}{|c|}{ Divisions } \\
\hline & & Aerospace \\
\hline \multicolumn{3}{|l|}{ Architectural Engineering } \\
\hline \multirow[t]{2}{*}{ Chemical Engineering } & Chemical Engineering & \\
\hline & Civil Engineering & \\
\hline \multicolumn{3}{|l|}{ Community Engagement } \\
\hline \multirow[t]{2}{*}{ Computers in Education } & Computers in Education & \\
\hline & & $\begin{array}{l}\text { Cooperative \& Experiential } \\
\text { Education }\end{array}$ \\
\hline \multirow[t]{2}{*}{ Educational Research and Methods } & $\begin{array}{l}\text { Educational Research and } \\
\text { Methods }\end{array}$ & Educational Research and Methods \\
\hline & Electrical \& Computer Engineering & Electrical \& Computer Engineering \\
\hline Energy Conversion \& Conservation & Energy Conversion \& Conservation & Energy Conversion \& Conservation \\
\hline \multicolumn{3}{|l|}{ Engineering Design Graphics } \\
\hline \multicolumn{3}{|l|}{ Engineering Libraries } \\
\hline & & Engineering Management \\
\hline \multicolumn{3}{|l|}{ Engineering Physics and Physics } \\
\hline & Engineering Economy & \\
\hline & Engineering Ethics & Engineering Ethics \\
\hline $\begin{array}{l}\text { Entrepreneurship and Eng } \\
\text { Innovation }\end{array}$ & & $\begin{array}{l}\text { Entrepreneurship and Eng } \\
\text { Innovation }\end{array}$ \\
\hline \multicolumn{3}{|l|}{ Environmental Engineering } \\
\hline & Engineering Technology & \\
\hline \multicolumn{3}{|l|}{$\begin{array}{l}\text { Experimental and Laboratory- } \\
\text { Oriented Studies }\end{array}$} \\
\hline First-year Programs & & First-year Programs \\
\hline \multicolumn{3}{|l|}{ Graduate Studies Division } \\
\hline \multicolumn{3}{|l|}{ K-12 and Pre-College Engineering } \\
\hline & Industrial Engineering & \\
\hline \multirow[t]{2}{*}{ Liberal Education Eng. \& Society } & Liberal Education Eng. \& Society & Liberal Education Eng. \& Society \\
\hline & & Mathematics \\
\hline Mechanical Engineering & Mechanical Engineering & \\
\hline Minorities in Engineering & & Minorities in Engineering \\
\hline \multirow[t]{2}{*}{ Multidisciplinary Engineering } & Multidisciplinary Engineering & \\
\hline & & Ocean and Marine Engineering \\
\hline \multicolumn{3}{|l|}{ Systems Engineering } \\
\hline Student & Student & Student \\
\hline Women in Engineering & Women in Engineering & Women in Engineering \\
\hline \multicolumn{3}{|c|}{ Zones/Sections } \\
\hline \multicolumn{3}{|l|}{ North Midwest } \\
\hline & Pacific Southwest & Pacific Southwest \\
\hline \multicolumn{3}{|l|}{ Southeast } \\
\hline Middle Atlantic & Middle Atlantic & \\
\hline
\end{tabular}


With the aim of further highlighting efforts taken to promote a diverse and inclusive workforce, this paper provides an overview of the top papers presented in 2015, 2016 and 2017. Taken together, these papers provide a rich tapestry showing the breadth of research being conducted that includes diversity and inclusiveness as focal areas.

\section{The Top Six Diversity Papers of 2015}

In total, 25 papers were nominated by 21 divisions and four Zones for consideration for Best Diversity Paper, 2015. There were six finalists invited to present; these papers were from the K12, First Year Programs, Liberal Education/Engineering and Society, Mechanical Engineering, Entrepreneurship and Engineering Innovation, and Multidisciplinary Engineering Divisions. The top papers presented at the conference included an exploration of changes in Latinx adolescents' perceptions of engineering self-efficacy and of engineering during a community-based engineering design experience [3], a baseline study on how engineering students identify as engineers and how they view the importance of diversity in engineering, [4], an autoethnographic study of the tensions between student values and the dominant discourse that he observed in an undergraduate engineering program [5], a research study exploring the cultures, structure, composition, and processes of a variety of student engineering teams [6], an exploratory study on the relationships between student characteristics such as socio-demographic traits and academic performance, and entrepreneurship education programmatic choices such as academic and co-curricular programs [7], redesigning a bridge experience that supports community college students' transition to university STEM programs [8]. The paper by Paguyo, et al., Creating Inclusive Environments in First-Year Engineering Classes to Support Student Retention and Learning, [4] was selected as the 2015 Best Diversity Paper.

Mejia, et al., [3] presented a paper nominated by the K-12 and Pre-College Engineering Division exploring Latinx adolescents' perceptions of engineering and their engineering abilities after participation in community-based design projects. Students were from working class families and most had parents with limited education who worked in farming or other manual labor activities. The adolescents, ages 14-17, worked in teams to identify a problem in their community and to use engineering design to solve the problem. Most of the participants changed both their perceptions of engineering as well as their self-efficacy as they worked on these projects. The design experience influenced participants' perceptions of engineering. The observed changes include a shift in perception of engineering work from building things to doing research, creating ideas, and helping people, and a shift from individual work to members of a team working toward a common goal; and change in perception of engineering as a field where females are active participants. In addition, participants' self-perceptions of how good they were at engineering improved through the community-based design experience.

Paguyo et al., [4] studied first year engineering students' perceptions of diversity in engineering. Participants were students in two engineering courses taken during the first semester in the engineering curriculum who completed a survey five times during their first semester. The survey included demographic information (sex, race/ethnicity), questions about diversity and professional identity, and questions about course activities. There was a lot of variation in engineering identity between students, and this was not explained by sex or URM status. However, engineering identity remained stable throughout the semester. Females showed a 
greater appreciation for diversity than males, and this difference remained constant throughout the semester although both showed a dip in appreciation for diversity in the middle of the semester. Activities centered on learning about real engineering practice were perceived as most valuable in developing self-efficacy. Discussion of engineering challenges was most influential in developing interest.

Brewer et al., [5] performed an exploratory on a non-traditional first year college student's experiences with messaging about engineering by an administrator, engineering faculty, and an academic advisor. Their ethnographic research revealed tensions between the career goals of the student and the prioritization of national economic strength, an emphasis on quantitative and technical aspects of engineering practice over social or qualitative aspects, and a focus on the importance of producing a large number of engineers to bolster the workforce over the educational goals of the students. The messaging is created and reinforced by individuals at different levels of the university system. This work underscores the need for critical introspection by educators on messaging about engineering, and a greater level of participation by students in constructing the messages about what engineering is and what it could be.

Walden et al. [6] studied the cultures, structure, composition, and processes of teams working on design competitions. Participants in this study were members of two teams working on two different undergraduate Student Experiential Learning Engineering Competition Teams (SELECT) design activities. The two teams exhibited differences in team organization and goals, but shared missed opportunities in terms of professional skills development through project teamwork. These professional competencies included effective leadership and management skills, and ability to interact with students having diverse backgrounds, knowledge and experiences. Using a Social Networks Perspective to analyze data from student and advisor interviews, researchers observed strong homophily and transitivity effects which create a culturally and demographically homogeneous environment and are directly linked to the missed learning opportunities. The authors present recommendations for mediating or preventing these effects through formalized education and mentoring.

In their study on pathways to entrepreneurial education, Celis and Huang-Saad [7] explored the relationships between student characteristics and entrepreneurship education programmatic choices in a Midwest research institution. The entrepreneurial activities included both cocurricular (start-up treks and a student incubator) and curricular (individual courses and a 9credit Entrepreneurship program) experiences. The student characteristics considered included demographic information (gender, citizenship, URM status), academic program, and academic performance as indicated by first semester and cumulative GPA. Data included records of 1,018 undergraduate students who participated in these activities between 2007-2013. Gender was found to be a factor in determining the type of entrepreneurial activity in which students participated; there was a greater representation of female students $(32 \%)$ in the curricular program in than in the co-curricular activities (22\%). Engineering majors represented a greater proportion of co-curricular activities than curricular activities. For female engineering students, the difference between curricular participation (21\%) and co-curricular participation (17\%) was not significant. No significant differences between curricular and co-curricular participation were observed based on citizenship or race/ethnicity. Participants in the co-curricular activities had a higher GPA than those who participated in the curricular programs. Statistically significant 
differences were observed both for initial GPA and cumulative GPA. This exploratory work will provide the foundation for a broader study on the entrepreneurial experience designed to help programs maximize entrepreneurial outcomes for students in all demographic groups.

Garland, et al., [8] describe a summer bridge program that supports minority STEM students' transition from community colleges to 4-year institutions. The New Mexico Alliance for Minority Participation Summer Community College Opportunity for Research Experience (New Mexico AMP SCCORE) is a residential summer bridge program that provides research and credit-bearing seminar opportunities at the host university. Participants in the SCCORE program also receive year-round advising to support transfer and articulation. The SCCORE program has strengthened ties between community colleges universities and strengthened collaborations with faculty in complementary programs. This has translated into several positive student outcomes. Of the 123 SCCORE participants between 2005- 2013, 85 (69.1\%) had transferred to a 4-year college; $50(58.9 \%)$ of those students had graduated with a Bachelor's degree, and the remaining $35(41.1 \%)$ were on track to complete their Bachelor's degree. Data from exit interviews were coded into three broad categories: transfer of knowledge, benefits of SCCORE, and modification of long-term plans including graduate school attendance. Feedback from faculty indicated that SCCORE represented an opportunity to groom students for participation in their research programs by working with them early in their academic careers.

\section{The Top Six Diversity Papers of 2016}

In total, 17 papers were nominated by 15 divisions and two zones for consideration for Best Diversity Paper, 2016. This included seven submissions from divisions/zones who had not submitted a nomination in 2015. Six finalists were invited to present. Topics included two papers on engineering design, one with a focus on ethical and contextual decisions later in the curriculum [9] and the second focused on problem framing and design considerations in the first year of the curriculum as a tool for underrepresented students to better identify their assets with engineering [10]. This paper, which reported on Mapping Assets of Diverse Groups for Chemical

Engineering Design Problem Framing Ability, by Svihla et. al. [10] was selected as the best 2016 Diversity paper. One of the finalists, Mikel, et al. was from the Pacific Southwest Section of ASEE [11]; this paper focused on nontraditional adult students and factors that impacted their acceptance in the student culture and persistence. A perspective-changing paper by Secules, Elby and Gupta [12] examined the individual to background to current climate contexts of students deemed 'not cut out' for engineering and provided strategies for engineering educators to structure their classrooms to reduce deficiency messaging. Welker [13] analyzed alumnae data from Villanova University gaining insights into persistence and undergraduate culture. Lastly, Yang and Grauer [14] reported on a loan repayment structure to address and counter financial factors impacting retention of women.

Gray et. al. [9] utilized a transdisciplinary education experience to grow students' ethical design decision abilities within the context and knowledge of social, contextual, and utilization impacts of engineering designs. Empathy was developed during the semester-long course as students sought to understand the context, resource limitations, and user factors when designing an offthe-grid toilet for use in remote or developing regions via a concurrent design course and humanities seminar. In addition to the technical expertise necessary to produce safe, effective, 
and efficient solutions, three ascending stages were used to help develop student empathy: "knowing (primarily cognitive), feeling (primarily emotional, and consistent with care ethics), and responding, (primarily action- oriented)." Empathetic development required vulnerability and safe spaces for students to exchange in discourse and cope with multiple perspectives in service of the user of the toilet. Research questions centered around the instructional strategies to foster empathy development and ascertaining the migration of student empathy over the semester-long course. An emergent thematic analysis enabled Gray and coauthors to identify strategies, approaches, and mindsets of students as they engaged with the target users in different regions with differing local ethics and practices as well as technical limitations with weather and wet/dry seasons. Feminism and gender issues were interwoven via coordination with the seminar course, but created a highly constrained environment that slightly improved understanding of gender/children/disability utilization of the toilets. Outcomes showed that student gained empathetic connections, but didn't uniformly connect this well with their final toilet designs and needed more explicit connections and examples. The author's noted that "because of the complex nature of the project, students tended to immerse themselves in the technical challenges they felt they could control, rather than the social challenges that appeared more daunting and less familiar."

Adult, nontraditional students over 25 in engineering were examined by Mikel et al. [11] using semi-structured interviews collected at a small private university, a community college, and a large public research university. Adult students formed "two types of relationships: viewing themselves as different from less mature and less committed traditional age students, and having mutual respect and admiration for the academic engagement of their traditionally aged peers or friends." Adult students across campuses felt socially excluded due to life commitments and challenges relating to traditional students. While class performance improved with the proportion of adult students, these students graduate at a lower rate than traditional students. Social integration was identified as a key to retention since anxiety leads to questioning abilities and thus stunted performance. Interviews revealed that Adult learners viewed themselves as more experienced, more career focused, and less interested in social activities than the traditional students. The authors conclude by encouraging educators to be cognizant of the challenges adult learners face and to proactively strive to develop group and team projects that better integrate adult learners with their peers.

Secules, Elby and Gupta [12] tackle the challenge of students deemed "not cut out" for engineering by examining the surrounding culture around that student in their article "Turning away" from the Struggling Individual Student: An Account of the Cultural Construction of Engineering Ability in an Undergraduate Programming Class. This paper is a perspective changing read as it makes visible "how the actions and interactions of many people, as well as institutional policies and societal values, work in concert to 'produce' the fact of someone not cut out for engineering." The explanations "locates the cause of such problems in broader cultural practices and interactions rather than in the individual students or their own 'mismatched' culture." The research explores the situation from the mindset that student or educational problems are not just mismatches in cultures, but are "systematically created events of marginalization." Class structure was identified as a means to make it possible for all enrolled to observe and judge who were the best and who were the worst programmers, so a novel programming class was designed and monitored via student interviews, video data of labs, and 
field notes. This paper strived to not point fingers, but instead unpack all the contributors (individuals and culture norms) to the situation. Data was analyzed from three stages: 1) individual problems were the result of the student's deficiencies, 2) societal/background forces produced the problem for the student, and 3) the culture within the classroom exacerbated and made public differences in background and maturity of knowledge to label future ability in the subject. As an example, "a lecture interaction pattern was sustained where high programming background students asked advanced questions." Since the questions were beyond the scope of the course, yet considerable time was devoted to them, only a small minority of the class understood the questions and answers, thus reinforcing confusion as well as who belonged and who did not. The author's use of "the theoretical lens of 'turning away' from a particular struggling student who was deemed 'not cut out for' engineering," this paper eloquently outlined "the ways that many other actors (students, teachers, societal labels, engineering culture) contribute to and construct this student ability in everyday moments." The final pitch is for all educators to view culture not as a past explanation for the current plight, but instead as a current challenge to create a desired, inclusive culture.

The team of Svihla et. al. [10] added an engineering design course early in the curriculum as a strategy to support persistence in engineering, especially with underrepresented groups. The goal was to help students discover and gain confidence in individual attributes, skills, and beliefs that are critical for engineering design. Those students best at framing problems had rated their own pre-college knowledge and confidence in engineering lower. The larger research effort entailed designing and refining an accessible tool to reveal assets diverse students bring as they enter engineering, ascertain if those assets vary by demographic, determine if the assets explain variance in performance, and illustrate the connection from the assets to engineering practice and identities. The products of this work include a well-vetted survey to assess assets, communication of the nonlinearity of design and importance of a value system, and most importantly turns on its head assumptions about skills viewed as deficiencies versus assets in diverse student populations and how this can be leveraged to reframe confidence and persistence in engineering. In conclusion, "identifying the strengths students bring could help faculty build on students' existing strengths. We should not view limited prior experience and low confidence as a deficit." This paper and presentation were judged the Best Diversity Paper of 2016 and as such, was also presented in the society-wide Best Paper Symposium at the 2017 Annual Meeting.

Welker [13] analyzed alumnae data to further explore the stats that women comprise $20-25 \%$ of BS degrees conferred in Civil Engineering, but only about $11 \%$ of practicing engineers. Women leave the engineering profession at a greater rate than men and cite the culture, management, isolation, salary, and lack of flexibility as reasons for no longer working in engineering. This research connected student experiences with persistence in the engineering workforce from a single private institution with female student and faculty female representations higher than the national average. The skills important in their profession reported by men and women were similar with women exhibiting a 5-percentage point higher rating for professional and ethical responsibilities and writing effectively. Women engineers conveyed during interviews that they wished they had learned strategies to deal with gender bias during their undergraduate years. Strategies to increase women's persistent included strengthening university-industry partnerships, not tolerating incivility, and to focus on teaching career management skills. 
Yang and Grauer [14] examined the financial factors impacting retention of women in engineering. The intervention studied was a loan repayment award provided by a private organization that was structured to provide incentive for degree completion by repaying subsidized student loans. Comparisons were made between a control group and an experimental group that received the loan repayment incentive. Both groups of women were randomly selected boasting similar initial GPAs, but the experimental group had higher final GPAs. Those completing out of both groups had similar GPAs, but the experimental group had statistically significant higher degree completion rates. The conclusions were that the loan repayment 'carrot' improved persistence for engineering student, most notably those with lower GPAs. This may be a useful tool to broaden the range of entering credentials that ultimately earn bachelor degrees in engineering and is a financial structure worth examining further at other institutions.

\section{The Top Five Diversity Papers of 2017}

In total, 17 papers were nominated by 16 divisions for consideration for Best Diversity Paper, 2017, including 2 papers submitted directly to the ASEE Diversity Committee, and one submitted by the Pacific Southwest. The finalists included submissions from three divisions/zones who had not previously submitted a nomination (Aerospace, Cooperative \& Experiential, and Mathematics). The top five papers selected to give presentations of their paper at the annual meeting included a paper centered on a mathematics course reform and its impact on closing the retention gap for underrepresented minority students and women [15], a research paper that described the experiences of LGBTQ engineering students relative to non-LGBTQ classmates at eight engineering programs across the United States [16], a paper that described the impacts of supplemental instruction on student success [17], a study that examined implicit bias in engineering [18], and a work in progress paper that described a new mobile aerospace-focused outreach initiative [19]. The paper by Cech, et al., reporting on The Inequality of LGBTQ Students in U.S. Engineering Education: Report on a Study of Eight Engineering Programs [16], was selected as the Best Diversity Paper, 2017. Below, these papers are briefly summarized.

Bullock, et al., [15] presented a paper nominated by the Mathematics Division that described the effects of a "Calculus Reform" on retention of students in STEM at a metropolitan university. They additionally described how this reform impacted student success in post-requisite coursework (e.g. in Calculus II, Dynamics, Fluids, etc.) The reform included a shift toward active learning pedagogies with students spending a majority of class time working in small groups on assignments designed along learning cycle principles to target one or two specific learning goals, and on making the problems in calculus have explicit relevance, with actual physical situations, units, and data. Their statistically significant results showed that across the board, all students benefited from the reformed calculus, $(3.4 \%$ increase in retention rate at the university). They noted a particularly profound effect occurring on STEM retention rate of women and underrepresented minority students (URM). Women who enrolled in the reformed calculus remained in STEM at a 9.1\% higher level; this arose from $4.2 \%$ women not shifting to non-STEM majors and 4.9\% women not dropping out of the university. Similar effects were noted for URM, who remained in STEM at a 9.4\% higher level, arising from $4.8 \%$ not shifting to non-STEM majors and 4.6\% not dropping out. The study demonstrated improvements in postcourse pass rates for all students who took the reformed calculus, with the largest improvements 
seen for URM and women. In summary, the authors noted that these increases in URM and women noted, effectively "closed the gap" previously seen at their university between retention of men versus women in STEM and in a retention rate for URM that exceeded non-URM students by $4.6 \%$.

Cech, et al., [16] submitted a paper that was nominated by the ASEE Diversity Committee that explored four different research questions that examined lesbian, gay, bisexual, transgender and queer (LGBTQ) inequality relative to the experiences of non-LGBTQ students at the same institution. Using data on over 1700 students from eight engineering colleges across the United States, questions focused on (1) whether LGBTQ students experience greater marginalization than their classmates, (2) whether their engineering work was more likely to be devalued, (3) whether LGBTQ students experience greater personal consequences than their peers in terms of stress, insomnia and happiness, and (4) whether these LGBTQ inequalities vary by school. Their results showed that LGBTQ students face greater marginalization, devaluation and personal consequences relative to their peers, and showed that there is little variation in the negative climate for LGBTQ students across the eight schools studied, which ranged from top-ranked engineering programs at public institutions to small, religiously affiliated private schools. The authors suggest a series of measures that might be taken to support LGBTQ students and to improve the climate of their programs, several of which are restated here. Measures might include, for example engaging faculty and students in "Safe Zone" trainings, (see https://diversity.asee.org/lgbtq) that educate students and faculty on appropriate language and inclusionary behaviors. Attention to language, e.g. through use of designated personal gender pronouns, using "partner," and more can also help create a more welcoming climate. Further, they suggest fostering a zero-tolerance policy for homophobic and transphobic joking and commentary.

Gegenheimer, et al., [17] presented research on Supplemental Instruction (SI), in which they explore the effects of a SI program in large enrollment classes at Louisiana State University, where underrepresented minority students make up $16.2 \%$ of the student population. This paper was nominated by the Student Division of ASEE. Ethnicity, gender and socioeconomic status, were demographic variables chosen for the study. Results show that all students improve their passing rates with increased session attendance, with the biggest gains in pass rate realized by African American, Asian and Hispanic students, respectively. In general, the greater the percentage SI attendance, the greater the increase in passing rate for all groups. The effects of math ACT scores against SI attendance was examined, showing that the trend of increasing pass rates with session attendance holds true for each minority group, regardless of entering math ACT level. The effects of gender, and of being in a group with low socioeconomic status were also examined; for example, students with low socioeconomic status perform lower than their peers with no participation in SI, however with SI attendance approaching 100\%, the initial gap in passing rates between these two groups of students is reduced from $9 \%$ to $2.8 \%$ with regular SI attendance. They note that minorities and females were found to be more likely to use SI than their peers. In conclusion, this study reinforces prior findings that show that SI is one of several programs that successfully decreases the academic performance gap between ethnic minority students and Caucasian. 
Li, et al., [18] were nominated by the ASEE Diversity Committee for their work on "Climate Control: Gender and Racial Bias in Engineering." This paper is focused on implicit bias in daily interactions focused on four areas, and at different stages for workplace process. A 38 Likert scale questionnaire asked members of SWE, the respondents, to rate their agreement level of statements describing experiences with implicit bias in the workplace. Results from over 3000 respondents with at least two years of work experience are reported. The research shows that, after controlling for age, education, workplace seniority and academic status, women still reported more "Prove-It-Again" bias, "Tightrope," and "Maternal Wall" bias than their male counterparts. "Prove-It-Again" bias refers to the documented studies that show that women and people of color often need to be more competent than white men in order to be seen as equally competent. "Tightrope," refers to pressure to behave in feminine ways, and backlash when women behave in masculine ways. "Maternal Wall" refers to documented studies that show that motherhood triggers strong negative competence and commitment assumptions. In addition, Asian and African-American engineers reported more "Prove-It-Again," and "Tightrope" bias than their white male counterparts. With more than 140 references, this paper forms an excellent reference point for developing an understanding of the literature surrounding nearly 40 years of research on these topics of bias.

The paper submitted by Rawat, et al., [19], titled "Mobile aerospace Education Lab: A NASA Supported K-12 Roadshow in a Box Initiative to Advance Aviation/Aerospace Education in Underserved Counties," was nominated by the Aerospace Division. This Work in Progress paper describes a new initiative focused on underserved counties in the region serving Elizabeth City State University, North Carolina. The initiative, supported in part by NASA, recently launched a mobile Aerospace Academy program for K-12 students, with an overarching aim of meeting regional workforce needs in an area that has experienced significant recent growth in the aviation and aerospace industry. The program is a traveling demonstration (Roadshow-in-a-Box) that is designed to foster (1) increased understanding of STEM content for students and teachers, (2) increased interest in pursuing STEM knowledge, degrees and careers, (3) increased community participation in STEM experiences, and (4) increased number of URM selecting a STEM major for post-secondary education. The program launched in January, 2017 and the 2017 ASEE presentation included feedback survey results from preliminary visits conducted in early 2017. The initiative, supported through a public-private partnership, reached more than 1500 students in its first several months.

\section{Summary}

A review of the 17 Best Diversity Paper finalists from 2015, 2016 and 2017 reveals cross-cutting interest and scholarship in diversity and inclusiveness, arising from 16 different divisions of ASEE when considering the finalists alone. More broadly, when considering the nominees from the divisions, a total of 59 papers were nominated for the Best Diversity Paper in 2015, 2016 and 2017, across 30 divisions, one committee and four regions. We conclude that the Best Diversity Paper provides the society with a wide-angle perspective on how divisions, committees and zones focus their efforts on broadening the diversity and inclusiveness of the engineering education profession. 


\section{Acknowledgments}

The authors acknowledge the leadership of ASEE for establishing the Diversity Committee in 2011, and for setting forth 2014-15 as the Year of Action on Diversity. This has resulted in a forum where divisions, committees and zones can submit knowledge acquired across the previous year by their members, and allowed a mechanism by which the diverse divisions, zones and committees of ASEE can highlight accomplishments in the area of Diversity to the ASEE community with the aim of further diversifying engineering education, and creating a broader workforce.

\section{References}

[1] http://diversity.asee.org/DiversityStatement downloaded 12/26/2017.

[2] http://diversity.asee.org/strategy downloaded 12/26/2017.

\section{Papers}

[3] Mejia, J. A., \& Drake, D., \& Wilson-Lopez, A. (2015, June), Changes in Latino/a Adolescents' Engineering Self-efficacy and Perceptions of Engineering After Addressing Authentic Engineering Design Challenges Paper presented at 2015 ASEE Annual Conference \& Exposition, Seattle, Washington. 10.18260/p.23678 https://peer.asee.org/23678

[4] Paguyo, C. H., \& Atadero, R. A., \& Rambo-Hernandez, K. E., \& Francis, J. (2015, June), Creating Inclusive Environments in First-year Engineering Classes to Support Student Retention and Learning Paper presented at 2015 ASEE Annual Conference \& Exposition, Seattle, Washington. 10.18260/p.23757 https://peer.asee.org/23757

[5] Brewer, M., \& Sochacka, N., \& Walther, J. (2015, June), Into the Pipeline: A Freshman Student's Experiences of Stories Told About Engineering Paper presented at 2015 ASEE Annual Conference \& Exposition, Seattle, Washington. 10.18260/p.24355 https://peer.asee.org/24355

[6] Walden, S. E., \& Foor, C. E., \& Pan, R., \& Shehab, R. L., \& Trytten, D. A. (2015, June), Leadership, Management, and Diversity: Missed Opportunities Within Student Design Competition Teams Paper presented at 2015 ASEE Annual Conference \& Exposition, Seattle, Washington. 10.18260/p.24396 https://peer.asee.org/24396

[7] Celis, S., \& Huang-Saad, A. (2015, June), Students Seeking Different Paths to Entrepreneurial Education Paper presented at 2015 ASEE Annual Conference \& Exposition, Seattle, Washington. 10.18260/p.24768 https://peer.asee.org/24768

[8] Garland, J. R., \& Auzenne, M. A., \& Jacquez, R. B. (2015, June), The Summer Undergraduate Research Bridge Experience for Community College Students: Providing Connections from Community College to the Four-year Institution Paper presented at 2015 
ASEE Annual Conference \& Exposition, Seattle, Washington. 10.18260/p.24913

https://peer.asee.org/24913

\section{Papers}

[9] Gray, C. M., \& de Cresce El Debs, L., \& Exter, M., \& Krause, T. S. (2016, June), Instructional Strategies for Incorporating Empathy in Transdisciplinary Technology Education Paper presented at 2016 ASEE Annual Conference \& Exposition, New Orleans, Louisiana. 10.18260/p.25746 https://peer.asee.org/25746

[10] Svihla, V., \& Datye, A. K., \& Gomez, J. R., \& Law, V., \& Bowers, S. (2016, June), Mapping Assets of Diverse Groups for Chemical Engineering Design Problem Framing Ability Paper presented at 2016 ASEE Annual Conference \& Exposition, New Orleans, Louisiana. 10.18260/p.25675 https://peer.asee.org/25675

[11] Mikel, T.K., \& Hoang, F.Q., \& Okada, E., \& Sung Hoe Kim, P., \& Rodriguez, A., Carnasciali, M.I., \& Ciston, S., A Multi-Institutional Study of the Relationships between Nontraditional and Traditional Undergraduate Engineering Students Paper presented at the 2016 American Society for Engineering Education Pacific Southwest Conference, Ponoma, CA.

[12] Secules, S., \& Elby, A., \& Gupta, A. (2016, June), "Turning away" from the Struggling Individual Student: An Account of the Cultural Construction of Engineering Ability in an Undergraduate Programming Class Paper presented at 2016 ASEE Annual Conference \& Exposition, New Orleans, Louisiana. 10.18260/p.26239 https://peer.asee.org/26239

[13] Welker, A. L. (2016, June), Where are they Now? Analyses of Alumnae Data Paper presented at 2016 ASEE Annual Conference \& Exposition, New Orleans, Louisiana. 10.18260/p.27198 https://peer.asee.org/27198

[14] Yang, Y. L., \& Grauer, B. (2016, June), The Effect of Financial Support on Academic Achievement and Retention of Female Engineering Students Paper presented at 2016 ASEE Annual Conference \& Exposition, New Orleans, Louisiana. 10.18260/p.26136 https://peer.asee.org/26136

\section{Papers}

[15] Bullock, D., \& Callahan, J., \& Cullers, J. B. S. (2017, June), Calculus Reform - Increasing STEM Retention and Post-Requisite Course Success While Closing the Retention Gap for Women and Underrepresented Minority Students Paper presented at 2017 ASEE Annual Conference \& Exposition, Columbus, Ohio. https://peer.asee.org/28000

[16] Cech, E. A., \& Waidzunas, T. J., \& Farrell, S. (2017, June), The Inequality of LGBTQ Students in U.S. Engineering Education: Report on a Study of Eight Engineering Programs Paper presented at 2017 ASEE Annual Conference \& Exposition, Columbus, Ohio. 
[17] Gegenheimer, J. B., \& Wilson, C. A., \& Steele, A., \& Waggenspack, W. N. (2017, June), Closing the Gap: Using Supplemental Instruction as a Tool to Assist Minorities in Engineering Paper presented at 2017 ASEE Annual Conference \& Exposition, Columbus, Ohio.

https://peer.asee.org/28042

[18] Li, S., \& Rincon, R., \& Williams, J. C. (2017, June), Climate Control: Gender and Racial Bias in Engineering? Paper presented at 2017 ASEE Annual Conference \& Exposition, Columbus, Ohio. https://peer.asee.org/28038

[19] Rawat, K. S., \& Lawrence, E. E., \& Gooden, O. D. (2017, June), Mobile Aerospace Education Lab (m-AEL): A NASA Supported K-12 "Roadshow-In-A-Box" Initiative to Advance Aviation/Aerospace Education in Underserved Counties Paper presented at 2017 ASEE Annual Conference \& Exposition, Columbus, Ohio. https://peer.asee.org/28675 


\title{
Appendix A
}

\section{Award for Best Diversity Papers Administered by the ASEE Diversity Committee}

\author{
Original Call for Diversity Best Papers (January, 2015)
}

\section{Award Description:}

The ASEE Board authorized 2014-2015 as the Year of ACTION on Diversity, wherein members will discuss, engage, and highlight individual and collective activities that serve to advance the Society's diversity efforts and inclusivity. This award strives to enhance the visibility and sustainment of actions in support of diversity. Engineering is empowering society in unprecedented ways. It is at the core of innovation and can address Grand Challenges facing the US and the world. In order for the engineering discipline to reach its full potential, however, the engineering education community and the engineering profession must better include all segments of our society. In particular, engineering must actively engage and help promote the pursuit of engineering education and engineering careers with those individuals who have been historically under-represented within engineering. ASEE believes that diversity and inclusiveness is essential to enriching educational experiences and innovations that drive the development of creative solutions in addressing the world's challenges. We learn from experiences, beliefs, and perspectives that are different from our own. Diversity, both intellectually and socially, fuels innovation and the development of imaginative and enduring solutions to global problems. The Diversity Committee's broad statement on Diversity is available here:

http://diversity.asee.org/DiversityStatement

The call for nominations for the Best Diversity Papers seeks to identify highly impactful efforts by ASEE authors that broaden participation in engineering and influence the inclusive, diverse future of engineering.

\section{Eligibility:}

\section{Mechanism \#1: Papers from the ASEE Annual Conference}

Individual reviewers are asked to nominate papers they review for the Best Diversity Paper Competition. Outstanding manuscripts that address any aspect of Diversity (see statement) may be nominated via the pull-down menu in the review window. The reviewers are asked to justify the basis for their nomination in their comments to the chair. Program chairs will compile the nominations for their division; each division has the latitude to select the best nomination from the division and forward to the ASEE Diversity Committee. Nominations by Program Chairs should include: division name, paper title, author(s), and electronic copy of the paper. All manuscripts nominated for best diversity paper will be flagged in the final annual meeting program.

\section{Mechanism \#2: Papers from any Section/Zone Conference}


Papers published within any section/zone conference proceedings between the dates of May 1 to April 30 of the respective calendar year may be nominated. Section/Zones have the latitude to develop/use any evaluation procedure to identify suitable papers and to select the best nomination from the section/zone. A section/zone may nominate 2 manuscripts for consideration by the ASEE Diversity Committee selection committee provided the manuscripts address different, but critically important, diversity-related topics. Nominations by Section/Zone Conference Chairs should include: section/zone name, conference date, paper title, author(s), and electronic copy of the paper.

Diversity dimensions addressed can include (but are not limited to): age, belief system, disability status, ethnicity, gender, gender identity, gender expression, national origin, race, sexual orientation, socio-economic status, and any other visible or non-visible differences.

\section{Award Selection Process:}

For both mechanism \#1 and \#2, program chairs and section/zone leadership are asked to submit their paper nominations to the ASEE Diversity Committee via email (diversity@asee.org) by the beginning of May. Award notifications will be sent in mid-May. Best Diversity Paper Awards will be presented in a special session at the ASEE Annual Conference.

Nominated diversity papers will be assessed for a) novelty of approaches/ideas/ interventions, b) extent of inclusivity, c) demonstrated impact, and d) communication effectiveness. The ASEE Best Diversity Paper rubric (http://diversity.asee.org/DiversityPaperRubric) will be utilized to assess scholarship attributes of the manuscript. The ASEE Diversity Committee will appoint a Selection Committee to review the papers. Members of this committee will also attend the presentation to select the Best Diversity Paper for presentation at the subsequent conference.

\section{Frequency of Award:}

Best Diversity Papers will be selected annually during the annual conference review process and concurrently from the section/zone meetings. Awards will be presented at the annual conference for which the papers were submitted in a dedicated session for the top 5 to 7 selected best diversity papers. This session will be organized by the ASEE Diversity Committee. The best paper/presentation from this best diversity paper session will be identified and forwarded to ASEE. This best of the best paper will be presented alongside the PIC best papers at the subsequent annual conference.

\section{Award Funding:}

For the inaugural year of the Best Diversity Papers, which coincides with the Year of Action on Diversity, the Mechanical Engineering Division of ASEE has committed $\$ 500$ to offer monetary awards during the Diversity Committee session. These awards will be $\$ 300$ for 
the Best Diversity Paper, $\$ 150$ for Second Best, and $\$ 0$ for Honorable Mention. The remaining $\$ 50$ will be used to purchase high quality plaques for the winners.

However, in subsequent years, the Best of the Best Diversity Paper Award will be funded in the same manner as all other ASEE Best Paper awards. 